\title{
Electrical characteristics of PVA-PANI-ZnS nanocomposite film synthesized by gamma irradiation method
}

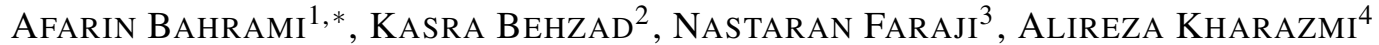 \\ ${ }^{1}$ Department of Physics, Islamshahr Branch, Islamic Azad University, Islamshahr, Iran \\ ${ }^{2}$ Department of Physics, Shahr-e-Qods Branch, Islamic Azad University, Tehran, Iran \\ ${ }^{3}$ School of Materials Science and Engineering, UNSW Australia, Sydney, NSW, Australia \\ ${ }^{4}$ School of Chemistry, University of New South Wales, Sydney, NSW 2052, Australia
}

\begin{abstract}
This work presents the synthesis of PANI-PVA-ZnS nanocomposite films by gamma irradiation approach. The samples were irradiated with different doses ranging from $10 \mathrm{kGy}$ to $40 \mathrm{kGy}$. Subsequently, structural, morphological, optical and electrical characteristics of the samples were investigated. Fourier transform infrared (FT-IR) spectroscopy was employed to study the chemical structure of the samples. Field emission scanning electron microscopy (FE-SEM) was used to investigate the morphology of nanocomposites. The electronic absorption characteristics of the samples were measured by means of UV-Vis spectroscopy. The AC and DC electrical behaviors of the samples were characterized using LCR meter in the frequency range of $20 \mathrm{~Hz}$ to $1 \mathrm{MHz}$. The impedance values of the samples were extracted from Cole-Cole plots and consequently DC conductivity was calculated.
\end{abstract}

Keywords: nanocomposite; polyaniline; FT-IR; LCR meter; impedance analysis

\section{Introduction}

Discovery of conductive polymers has made it possible to employ these substances as a low cost substitute, modifier or reinforcement for metallic and semiconductor materials $[1,2]$. Among conducting polymers, polyaniline (PANI) has attracted much interest of many researchers due to its tunable properties and high conductivity, good environmental and thermal stability, ease of synthesis and many potential applications [3-5]. PANI has been found in different forms raging from insulating to conducting.

The combination of zinc sulphide $(\mathrm{ZnS})$ nanoparticles and PANI is an interesting composite for optical, electrical and medical applications because of variable properties of PANI at different oxidation states as well as functional properties of the $\mathrm{ZnS}$ nanoparticles with the wide range of band gap. Incorporation of these two materials combines and enhances the properties of both phases.

*E-mail: afarin.bah@gmail.com
PANI-ZnS nanocomposite is a new subject with a tremendous potential into the various applications, which makes it interesting to investigate. To the best of our knowledge, this compound has been scientifically studied in six different studies [6-11]. At present, two methods are used for the preparation of $\mathrm{ZnS} /$ conducting polymer composites: the dispersion of $\mathrm{ZnS}$ nanocrystals in polymer solution and the chemical polymerization of the monomer in the presence of $\mathrm{ZnS}$ nanoparticles [10]. The method of synthesis has a direct impact on chemical and physical properties of the final product. Therefore, finding a cheap, easy and processable method would be crucial for the large area application.

PANI shows better processability upon addition of another water-soluble polymers such as polyvinyl alcohol (PVA). Besides, PVA with the molecular formula of $\left(\mathrm{C}_{2} \mathrm{H}_{4} \mathrm{O}\right)_{n}$ is a viscous medium or capping agent which provides flexibility, processability and control of the growth of nanoparticles [12].

In this study, we synthesized PVA-PANI-ZnS nanocomposite films by a single step in situ 
polymerization of PANI and simultaneous reduction of $\mathrm{ZnS}$ nanoparticles with the help of ionizing radiation. Gamma radiation has been considered as an interesting route since no oxidizing agent, reducing agent and metallic catalyst is required. It provides a pure product at a low cost. In addition, this process can be done in a solid state condition with a possibility of size control.

\section{Materials and methods}

Polyvinyl alcohol (PVA, Mw 30,000 g/mol, $98 \%$ hydrolyzed) was purchased from Merck Company and used as a binder. Aniline hydrochloride (AniHCl, Mw $129.59 \mathrm{~g} / \mathrm{mol}$ ) and thioacetamide $\left(\mathrm{CH}_{3} \mathrm{CSNH}_{2}\right)$ were supplied by SigmaAldrich and used as precursors. Zinc acetate $\left(\mathrm{Zn}\left(\mathrm{CH}_{3} \mathrm{COO}\right)_{2} \cdot 2 \mathrm{H}_{2} \mathrm{O}\right)$, purchased from $\mathrm{R} \& \mathrm{M}$ Chemicals was used as a source of zinc. All materials were used without any further purification.

In a typical procedure, the PVA solution was prepared by dissolving $30 \mathrm{~g}$ PVA powder in $600 \mathrm{~mL}$ deionized water at room temperature in a water bath at fixed temperature of $80{ }^{\circ} \mathrm{C}$ for 2 hours. The solution was then left to cool at room temperature.

After temperature equilibration, $12 \mathrm{~g}$ of aniline hydrochloride was added into $600 \mathrm{~mL}$ PVA solution. The same molar ratio $\left(1: 1 \times 10^{-3} \mathrm{~mol} / \mathrm{L}\right)$ of zinc and sulphur source was also added to the PVA solution. The mixture was continuously stirred for 10 hours in nitrogen atmosphere. The blend solution was divided into $50 \mathrm{~mL}$ portions and poured into a specially made glass caster. The casted solutions were left to dry at ambient temperature in a dark room for at least 6 days. The films were removed and cut into several pieces with the dimension of $2.5 \mathrm{~cm} \times 2.5 \mathrm{~cm}$. The thickness of the samples was determined by a digital micrometer model Mitutoyo No. 293-521-30-Japan. The average thickness of the films was $0.12 \mathrm{~mm}$. The casted films were packed in six sealed plastic bags and sent for gamma irradiation from $0 \mathrm{kGy}$ to $40 \mathrm{kGy}$. The samples were exposed to gamma irradiation at the room temperature using ${ }^{60} \mathrm{Co}$ producing gamma rays with the average energy of $1.25 \mathrm{MeV}$.

\section{Results and discussion}

The FT-IR spectrum of PVA-PANI-ZnS film is shown in Fig. 1. The PVA film is used for setting the background. The IR signatures indicate presence of both emeraldine base (EB) and emeraldine salt (ES) forms of PANI [13]. EB-polyaniline is the neutral and the most stable form of PANI at room temperature. It can form ES-polyaniline followed by protonation and exhibit electrical conductivity.

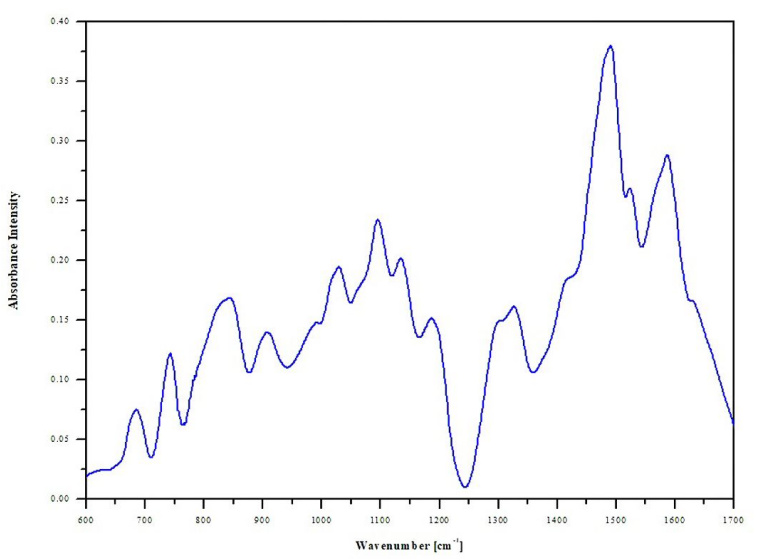

Fig. 1. FT-IR spectrum of PVA-PANI-ZnS nanocomposite film.

The FT-IR result indicates that $\mathrm{HCl}$ of Ani$\mathrm{HCl}$ precursor is dissociated and forms free radicals of $\mathrm{H}^{+}$and $\mathrm{Cl}^{-}$as the consequence of gamma irradiation. Subsequently, $\mathrm{Cl}^{-}$radicals are doped on amine group and form the protonated state of PANI. The doping process creates a local distortion, resulting in a local polarization, centred on the charge carriers, that is known as polaron. Therefore, the protonation process produces the polarons and consequently results in high electrical conductivity.

The bands at $1592 \mathrm{~cm}^{-1}$ and $1495 \mathrm{~cm}^{-1}$ are assigned to the quinoid and benzoid ring stretching vibrations. Higher absorbance intensity of benzoid ring vibration confirms that the formed PANI is mainly at ES state. The peaks centred at $1335 \mathrm{~cm}^{-1}$ and $1305 \mathrm{~cm}^{-1}$ correspond to $\mathrm{C}-\mathrm{N}$ stretching vibration. The peaks in the region of $1000 \mathrm{~cm}^{-1}$ to $1200 \mathrm{~cm}^{-1}$ are attributed to the in plane bending vibration of aromatic $\mathrm{C}-\mathrm{H}$. 
The peak at $850 \mathrm{~cm}^{-1}$ is characteristic of $\mathrm{C}-\mathrm{H}$ out of plane bending vibration. The bands at $747 \mathrm{~cm}^{-1}$ and $693 \mathrm{~cm}^{-1}$ are due to the mono-substitution on the benzene ring [13-17].

The morphology images of PVA-PANI-ZnS nanocomposite films subjected to $10 \mathrm{kGy}$ and 40 kGy irradiation are shown in Fig. 2a and Fig. 2b, respectively. It can be seen in Fig. 2a that $\mathrm{ZnS}$ nanoparticles (bright spherical objects) and PANI nanoparticles are spherical and agglomerated. At higher dose of radiation more PANI nanoparticles are formed and agglomerated while $\mathrm{ZnS}$ nanoparticles are dispersed within the PANI structure. Therefore, at higher dose, a tight uniform structure of the nanocomposite is formed.

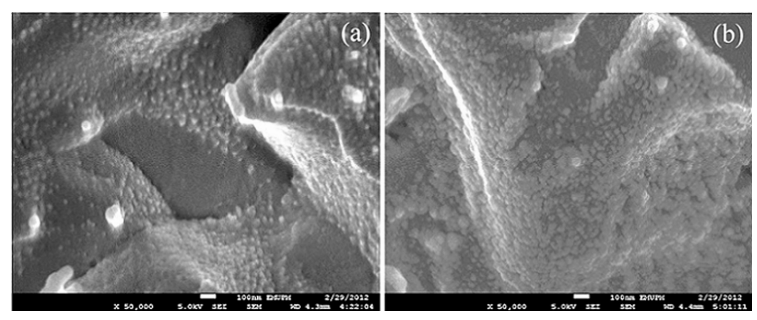

Fig. 2. FE-SEM images of PVA-PANI-ZnS nanocomposite films synthesized at (a) $10 \mathrm{kGy}$ and (b) $40 \mathrm{kGy}$ gamma irradiation.

Electronic absorption spectra of PVA-PANI$\mathrm{ZnS}$ nanocomposite films are depicted in Fig. 3. The PVA film is set as the background. Both spectra reveal 5 main absorption peaks centred at $252 \mathrm{~nm}$, $309 \mathrm{~nm}, 405 \mathrm{~nm}, 580 \mathrm{~nm}$ and $805 \mathrm{~nm}$. The first peak at $252 \mathrm{~nm}$ is due to the polyanilinum cations and becomes smaller at $40 \mathrm{kGy}$ irradiation indicating higher polymerization of PANI at higher doses. The peak observed at $309 \mathrm{~nm}$ confirms the formation of $\mathrm{ZnS}$ nanoparticles [18]. The peak centred at $580 \mathrm{~nm}$ is associated with the exciton transition of quinoid in the undoped state of PANI (EB) and the other two bands at $405 \mathrm{~nm}$ and $805 \mathrm{~nm}$ are due to polaron band transitions, indicating formation of conducting form of PANI (ES) [19]. Therefore, similar to FT-IR result, it is confirmed that PANI is present in both EB and ES forms. As the dose of radiation increases, the intensities of the peaks at $405 \mathrm{~nm}$ and $805 \mathrm{~nm}$ is increasing, indicating the formation of more doped state of PANI. Consequently, the formation of more doped state would increase the conductivity of the sample irradiated at higher dose.

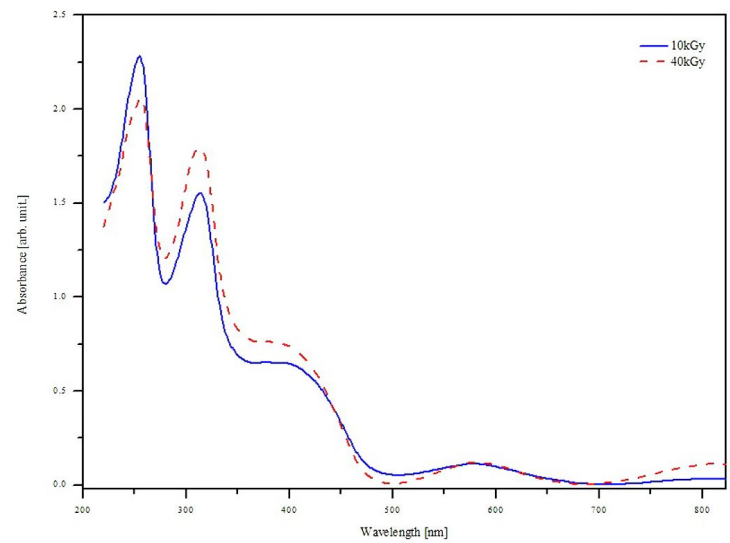

Fig. 3. UV-Vis spectra of PVA-PANI-ZnS nanocomposite films synthesized at $10 \mathrm{kGy}$ and $40 \mathrm{kGy}$ gamma irradiation.

Fig. 4 shows the general conductivity of PVA and PVA-PANI-ZnS as a function of frequency for gamma irradiated samples from $10 \mathrm{kGy}$ to $40 \mathrm{kGy}$. The general conductivity plot is a combination of both real and imaginary part of conductivity. The general conductivity of the samples has increased compared to PVA.

According to Jonscher et al. [20], the conductivity is the summation of direct current (DC) conductivity and alternating conductivity (AC), which can be expressed as:

$$
\sigma(\omega)=\sigma_{D C}(0)+\sigma_{A C}(\omega)
$$

The DC conductivity is a consequence of free charge carriers. The movement of these carriers in the applied electrical field is independent of frequency. In contrast, the AC conductivity arises form trapped charge carries or ions. Therefore, according to the known mechanism of ionic hopping, an alternating filed with a certain frequency causes the movement of ions from one centre to another.

At lower frequency, conductivity behaves independently of frequency representing DC conductivity. At higher frequency, conductivity shows 


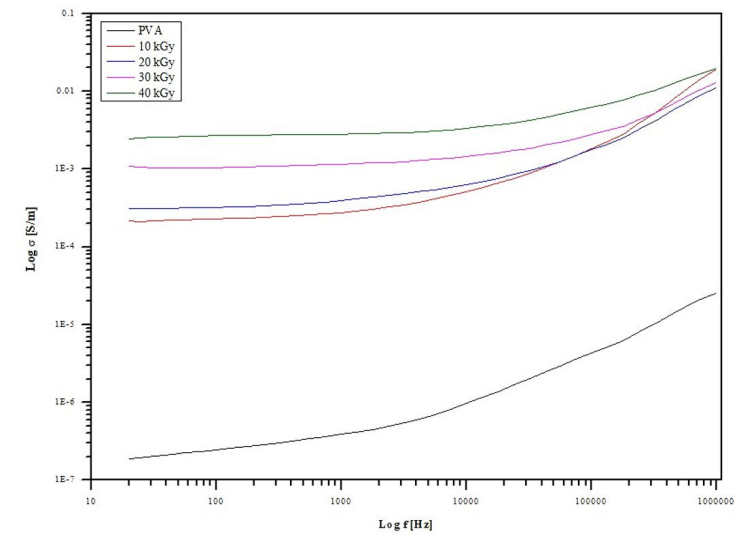

Fig. 4. General conductivity of PVA-PANI-ZnS samples irradiated from $10 \mathrm{kGy}$ to $40 \mathrm{kGy}$.

frequency dependency and the $\mathrm{AC}$ conductivity becomes more dominant. The AC conductivity behavior at higher frequency is due to the trapped ions within the nanocomposite matrix. As the gamma irradiation is increasing, the frequency dependent conductivity shifts toward higher frequency. The shift of dispersion and increment of conductivity as a function of gamma irradiation indicates the less concentration of trapped ions and increased formation of free charge carriers within the film matrix.

Fig. 5 shows the Cole-Cole plots of PVA-PANI$\mathrm{ZnS}$ samples from $10 \mathrm{kGy}$ to $40 \mathrm{kGy}$ gamma irradiation. The plot of complex impedance $Z^{\prime \prime}$ vs. $Z^{\prime}$ results in a semicircle graph in which the equivalent circuit is in a form of a capacitance in parallel with a resistance. This indicates that the grains are the main participants in conductivity and charge transfer while the grain boundaries have no effect on conductivity. This result is in agreement with the FE-SEM image, which shows a uniform polymerization within the film matrix.

Impedance $\mathrm{Z}_{0}$ is obtained by extrapolating the semicircle curves to the real impedance axis $Z^{\prime}$ at zero frequency. The DC conductivity is then calculated by:

$$
\sigma_{D C}=\frac{d}{A \times Z_{0}}
$$

where $\mathrm{d}$ is the thickness and $\mathrm{A}$ is the surface area of film.

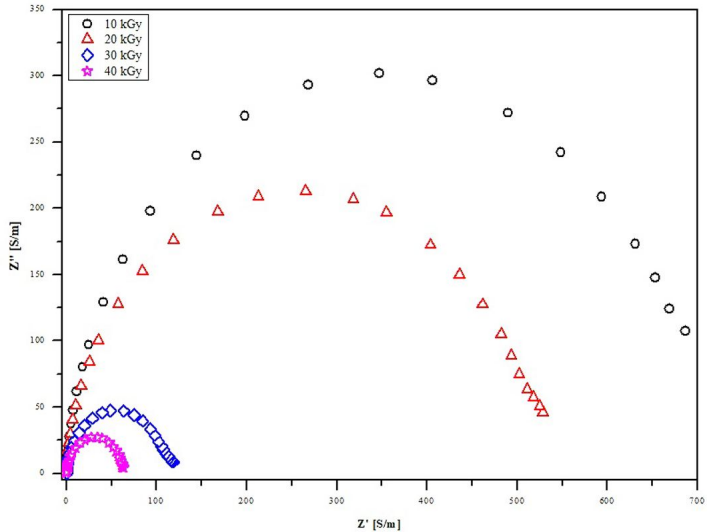

Fig. 5. Cole-Cole plots of PVA-PANI-ZnS nanocomposite films irradiated from $10 \mathrm{kGy}$ to $40 \mathrm{kGy}$.

The measured values of DC conductivity are $2.47 \times 10^{-7} \mathrm{~S} / \mathrm{m}, 2.1 \times 10^{-4} \mathrm{~S} / \mathrm{m}, 2.98 \times 10^{-4} \mathrm{~S} / \mathrm{m}$, $1 \times 10^{-3} \mathrm{~S} / \mathrm{m}$ and $2.6 \times 10^{-3} \mathrm{~S} / \mathrm{m}$ for PVA, samples irradiated at $10 \mathrm{kGy}, 20 \mathrm{kGy}, 30 \mathrm{kGy}$ and $40 \mathrm{kGy}$, respectively. The DC conductivity has increased by increasing the gamma irradiation dose from $10 \mathrm{kGy}$ to $40 \mathrm{kGy}$. The increase in DC conductivity is due to the formation of higher amount of ES state of PANI, as a result of higher concentration of free charges present in the sample. It is worth to mention that the conductivity of PVA has increased by a factor of almost 10000 after polymerization of PANI at $40 \mathrm{kGy}$.

\section{Conclusions}

The PVA-PANI-ZnS nanocomposite was successfully synthesized by gamma irradiation method at $10 \mathrm{kGy}$ to $40 \mathrm{kGy}$ radiation doses. The FT-IR spectroscopy indicated the presence of EB and ES forms of PANI wherein the ES form was responsible for electrical conductivity of the samples. The FE-SEM images showed the formation of spherical $\mathrm{ZnS}$ and PANI nanoparticles where the PANI particles were agglomerated along the matrix. The PANI nanoparticles formed a uniform structure at higher dose. The UV-Vis spectroscopy also confirmed the formation of $\mathrm{ZnS}$ nanoparticles and both EB and ES forms of PANI. The result indicated that large quantity of ES was formed at higher dose. The electrical properties of the samples were enhanced 
by increasing the gamma irradiation doses because of formation of higher amount of ES form of PANI. The measurements of impedance and DC conductivity revealed a significant increment in conductivity of the samples by a factor of $10^{4}$.

\section{Acknowledgements}

We acknowledge the Islamshahr Branch of Islamic Azad University for providing the research facilities for us to carry out this research.

\section{References}

[1] Bahrami A., Talib Z.A., Yunus W.M.M., BeHZAD K., AbDi M.M., Din F.U., Int. J. Mol. Sci., 11 (2012), 14917.

[2] Wu H., Yu G., Pan L., LiU N., Mcdowell M.T., Bao Z., Cui Y., Nat. Commun., (2013), 1943.

[3] Dutta P., Biswas S., Ghosh M., De S.K., ChatTERJEE S., Synthetic Met., 2 (2001), 455.

[4] LUZNy W., BANKA E., Macromolecules, 2 (2000), 425.

[5] Ghosh P., Siddhanta S.K., Chakrabarti A., Eur. Polym. J., 4 (1999), 699.

[6] Tuncer E., Turac E., Adv. Polym. Tech., 4 (2013), 21373.

[7] Dutta K., Manna S., De S.K., Synthetic Met., 3 - 4 (2009), 315.

[8] Pant H., Patra M., Negi S., Bhatia A., VAdera S., Kumar N., Bull. Mater. Sci., 4 (2006), 379.
[9] Amrollahi Bioki H., Borhani Zarandi M., Indian. J. Phys., 6 (2012), 439.

[10] Scocioreanu M., Baibarac M., Baltog I., PaSUK I., Velula T., J. Solid. State. Chem., (2012), 217.

[11] Scocioreanu M., Mihut L., Baibarac M., BalTOG I., Phys. Status. Solidi. B, 7 (2013), 1426.

[12] Gautam A., Tripathy P., Ram S., J. Mater. Sci., 10 (2006), 3007.

[13] Wei X., Wang Y., Long S., Bobeczko C., EPSTEIN A., J. Am. Chem. Soc., 11 (1996), 2545.

[14] Yu Y., Che B., Si Z., Li L., Chen W., Xue G., Synthetic Met., 3 (2005), 271.

[15] Konyushenko E.N., Stejskal J., ŠEdĚnková I., Trchová M., Sapurina I., Cieslar M., Prokeš J., Polym. Int., 1 (2006), 31.

[16] Zhang Z., Wan M., Synthetic Met., 1 (2002), 83.

[17] Trchová M., Konyushenko E.N., Stejskal J., Kovářová J., Ćirić-Marjanović G., Polym. Degrad. Stabil., 6 (2009), 929.

[18] Kharazmi A., Faraji N., Hussin R.M., Saion E., Yunus W.M.M., BEHZAD K., Beilstein J. Nano., 1 (2015), 529.

[19] LiU W., Kumar J., Tripathy S., Senecal K.J., SAMUelson L., J. Am. Chem. Soc., 1 (1999), 71.

[20] Jonscher A.K., Frost M.S., Thin Solid Films, 2 (1976), 267.
Received 2017-06-03

Accepted 2018-02-10 